\title{
EFFECTIVE USE OF E-MAIL MARKETING ON EXAMPLE OF SMALL AND MEDIUM-SIZED ENTERPRISES IN SERBIA
}

\author{
Maja Obradović, \\ Slavko Alčaković, \\ Ognjen Pavlović
}

Singidunum University, Belgrade, Serbia

Correspondence:

Maja Obradović

e-mail:

mobradovic@singidunum.ac.rs

\begin{abstract}
:
In the world of modern business, new marketing tools created in line with the Internet and new technologies, are being integrated into communication strategies. Email marketing is increasingly recognized as a cost-effective tool for small and medium-size enterprises (SMEs). Most of the companies which are doing business in Serbia are organized as small and medium-sized enterprises. The aim of this paper was to analyze the usage of e-mail marketing as a strategy for small and medium-sized enterprises (SMEs) in Serbia. Also, this paper aims to analyze employee's knowledge regarding e-mail marketing, usage of e-mail marketing tactics, the use of e-mail services, the practical problems that emerge and to analyze the potential for combining the e-mail marketing with other marketing strategies and platforms. The research was conducted in the form of questionnaire and included respondents in the fields of IT, marketing and other related areas. Our paper quantifies the benefits of email marketing with the showcase of results from the practical usage of email marketing. It has clear implications for the firms that are starting to design their email marketing campaign.
\end{abstract}

Keywords:

Marketing, E-mail marketing, SME, Communication strategies.

\section{INTRODUCTION}

The development of new technologies has changed business and marketing practices. Changes are caused by globalization as a global phenomenon. The benefits of the globalization and new technologies have a significant impact on the development of the economy in order to increase efficiency, cost-effectiveness and build a good communication system between the participants on the global market. [1] New changes caused by globalization bring many opportunities for further development in the world of business, whether it's about large, small or mediumsized enterprises. New opportunities have also brought many challenges for companies which are doing business in the digital age. Companies are using different types of communication strategies to target and interact with customers. The main reason for involving different types of communication strategies are different groups of customers with different needs on different platforms. Companies need to compare costs and benefits of communication channels and choose the most efficient ones. 
Besides the traditional media, there are new media and new channels in the era of digital. Development of internet changed the way of communication and interaction between companies and customers. A growing number of companies and enterprises actively use the Internet and other electronic tools to communicate with suppliers, business customers and end users of their products and services [2].

The number of companies which are using e-mail in their everyday communication is increasing day by day. Unlike the traditional marketing channels, there are many advantages when it comes to e-mail marketing. The main reason is simple - e-mail is a cheap, fast and reliable way of communication, available to many people. Therefore, e-mail as a marketing channel is very interesting for entrepreneurs. Even though it has many challenges, e-mail marketing has a lot of opportunities for entrepreneurs and marketing experts. If they choose to integrate e-mail marketing into their communication strategies, it could be a good solution for sale increase and development of enterprises. Even it is a fast, cheap and reliable channel, it doesn't mean that companies shouldn't plan and create strategies and tactics for using e-mail marketing in everyday business. It should be well combined and harmonized with the other business goals of a company and marketing strategy. If the companies are involving the e-mail marketing without any plan and strategy it may bring them more damage than utility.

Large, small and medium-sized companies are the most often forms of company organization. According to SBA report from 2017, the total number of enterprises in Serbia is 300.973. SMEs are the most numerous ones - 300.500 in total.[3] The number of employees in SMEs in Serbia is rapidly increasing since 2014. According to data from 2017, the total number of employees in SMEs in Serbia is 772.766 [3]. Since there are many small and medium-sized enterprises in Serbia whose main goal is to decrease cost and achieve efficiency and effectiveness, the authors examined the usage of e-mail strategies as one of the most important elements of modern business success.

The aim of the research was to analyze the use of e-mail marketing and e-mail marketing strategy knowledge by entrepreneurs and employees in Serbia.

\section{LITERATURE REVIEW}

As a result of low entrepreneur's budgets, e-mail marketing is one of the most recommended strategies for small and medium-sized business. It is an example of a cheap and accurate way of marketing to target new customers, keep contact with existing customers and increase sale. E-mail marketing, as a powerful tool for building long-term relations with consumers is a form of direct marketing which implies direct access to the target audience [4] It is a form of direct marketing that uses electronic means to deliver commercial messages to an audience; one of the oldest and yet most powerful of all digital marketing tactics [5] E-mail marketing implies sending e-mails to the list of subscribers- people who subscribed to an e-mail list of a company [6]. It could be used as a tool for acquisition or a tool for retention [7].

E-mail marketing often implies the use of mobile. The reason is a major number of users who are actively using mobile phones and very often they read e-mails on mobile devices. According to studies, a major number of users are first to open e-mails on mobile, rather than desktop. By the end of the 2017 results shows that mobile (47\%) has the lead as a device for e-mail opening. In the second place there is a webmail (36\%), and on the third is desktop (17\%).[8] When it comes to using mobile for e-mail opening, companies should have in mind that the content must be created and designed by specific standards- the size of the mobile screen, different mobile operating system, touch screen instead of mouse click. [5]

Email marketing offers an opportunity for personalized communication. It allows to segment and targets the audience by different criteria. Better personalization leads to better response rate. Research shows that personalization of e-mail campaign can increase response rate up to $45 \%$. [9]

Research shows that in today's world consumers are "attacked" with more than a 3000 information per day, either they came through the traditional or new e media, and the most of them are considered to be unwanted. [4] According to previous literature, [10] there are two types of marketing- interruption marketing and permission marketing. Interruption marketing implies distracting consumers by interrupting the current consumer activities. Unlike the interruption marketing, permission marketing requires the existence of customer permission to be involved in marketing activites of a company in exchange for some kind of incentive and stimulus [9]. One of the theories behind permission marketing is that, presumably, a customer who has given permission to receive promotions is a better, more loyal, and more profitable customer overall. [11]

Unlike the other forms of marketing, in e-mail marketing people willingly give their contact information. 
This is one of the reasons why e-mail marketing has been so successful. Also, there is more control, because people can unsubscribe from the list and stop receiving e-mails from the company.

When it comes to types of message content, e-mails can contain different messages- promotional messages which are directly connected with sale or information messages just to share content interesting to customers. Call to action is required part of every e-mail message. CTA is focused on motivating the consumers threw a written phrase, in order to challenge and encourage consumer reaction on promotional message.

E-mail marketing has a lot of advantages, compared to other marketing channels. The low price, the possibility of segmenting customers, measurability, and the possibility of control are some of them. [12] E-mail marketing requires much less cost than traditional marketing and shows a much higher return on investment. According to [13], e-mail marketing campaigns produce approximately twice the return on investment in comparison with other forms of online marketing such as web banners and online directory adverts. E-mail marketing has the highest ROI and also represents the best type of marketing for increasing engagement of existing customers. [14]

As in the case of the other marketing tools, e-mail marketing has a few disadvantages. The increase of email list, e-mails which are not opened and users unsubscribing from the list are only some of those. In order to use e-mail marketing, companies must have a list of subscribers. Creation, growth, and development of this list are one of the biggest problems for a large number of companies. When it comes to e-mails which are not open, there are several techniques for the increase, depending on how much information the company has about the user. The general rule is that if the message is more personalized, more e-mails will be opened. Preventing users to unsubscribe from a list is a problem for many companies which use e-mail marketing. There are many reasons for users to unsubscribe from the list, and one of the most common is the frequency of receiving e- mails from companies. By doing research and having well-formed strategies and tactics of communication, companies can have a significant impact on the reduction of unsubscribed users.

E-mail marketing strategy could be divided into three phases. The first phase concerns the strategies used to get an e-mail from a website visitor. The second phase is communication with customers, sending promotional and other messages with the main goal of encouraging a sale. The third phase is following up the communication with the customer in post-sale in order to maintain the contact and incentive for re-purchase.

When it comes to phase one, the most important strategy is a lead magnet. It implies the use of free content/resource which has been given to web site visitor in return for his e-mail address. The free resource has many forms and it depends on the industry and companies core business. In practice, the most often free contents are free eBooks, videos, audios or some kind of discount. Companies should have in mind that the content must be useful and wanted by customers.

The second phase of e-mail marketing begins when a customer subscribes to a list and it usually lasts until customer transfers to buying list or unsubscribes from the company list. The usage of content marketing is the main characteristic in phase two.

The focus of the third phase is building better relations- encouraging and developing loyalty to the brand and company. In the world of alternatives, one of the main goals of companies, besides the profit, is to build a long-term relation with customers in order to build customers loyalty.

In order to make the success of using email marketing as efficient as possible, companies need to use different email marketing tactics. According to previous research, there is a list of e-mail marketing tactics which companies can use in their communication strategies.

Length of e-mail, headline, brand logo, personalization and frequency and timing of e-mail are just some of them. Length of e- mail shows a page length as a dimension of all e-mails and usually the length of e-mail is ranged from 1 to 5 pages with an average length of 2.4 pages. [15] The headline is very important in e-mail strategies. The content of headline should grab the attention of the recipient and attract recipient to open and read e-mail. The brand logo is used in almost every e-mail. According to previous research, logos were used in $99 \%$ and the most often position for the brand logo is the top left-hand section of the first page.[15] Personalization is often used in e-mail communication and the main goal is improving click-through rates. Click- through rate is defined as the total clicks on a link divided by the number of times that link was shown, expressed as a percentage[5]. The frequency and timing of e- mail is crucial. Companies should balance between too many and too few- too many might irritate and too few could lose the recipient's interest [15]. Depending od what is the main product/ service which is promoted in e-communication, companies also should 
pay attention to the day, time of the year or seasonality of the product/ service to stimulate the potential customers in the right time.

As a tool which shows an increase in sales, there are many research results which are pointing to the efficiency of using e-mail in marketing business strategies. According to the survey of 2000 customers of Datatron company showed that $80 \%$ of their customers found e-mail as their most powerful marketing tool, as it was the first place on that list [16].

Previous research also showed that customers who received an e-mail from a company found it to be useful, interesting and appreciated in between communication [17]

This research is among the first ones that addressed email usage in SMEs in Serbia. According to the authors, no research has been done in Serbia so far on this topic.

\section{METHODOLOGY AND RESULTS}

The research was conducted in Belgrade in October 2017 in the form of a questionnaire. There were 41 respondents who answered on 23 different questions. All respondents worked in small and medium-sized enterprises. Most of the respondents $(53,7 \%)$ were working in the fields of marketing and IT. Results showed that almost $60 \%$ of respondents were familiar with benefits and e-mail marketing in general, and $14.6 \%$ were actively using e-mail marketing in everyday business.

In the questionnaire, there were four parts. Part 1 - Email marketing tactics, Part 2 - the usage of E-mail service, Part 3- Practical problems, Part 4 - Combining the e-mail marketing with other marketing strategies and platforms.

According to the results, main reasons for using the e-mail marketing in company strategies were sale increase (36.6\%), customer relationship (26.8\%) and new product marketing (26.8\%).

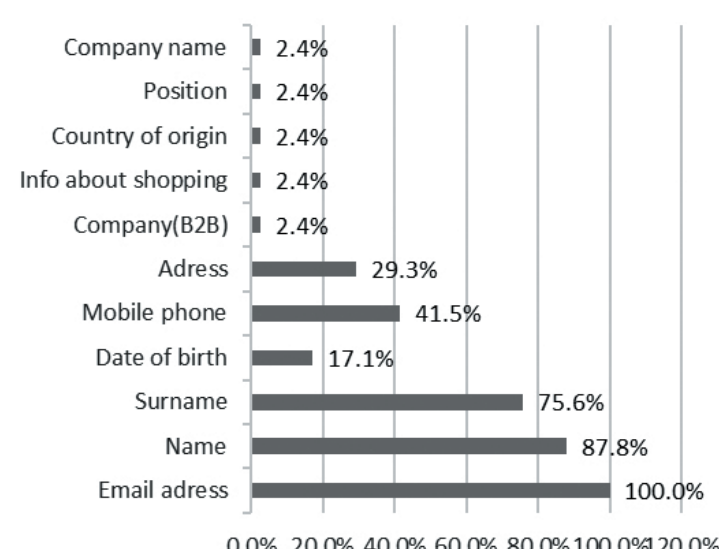

Fig.1. Information about customers
According to Fig.1., besides the e-mail address, name, surname and mobile phone number were the usual information which companies collected about their customers. By collecting the right information, companies have a better chance to segment and personalize messages intended for their target group in order to achieve communication goals and sale increase.

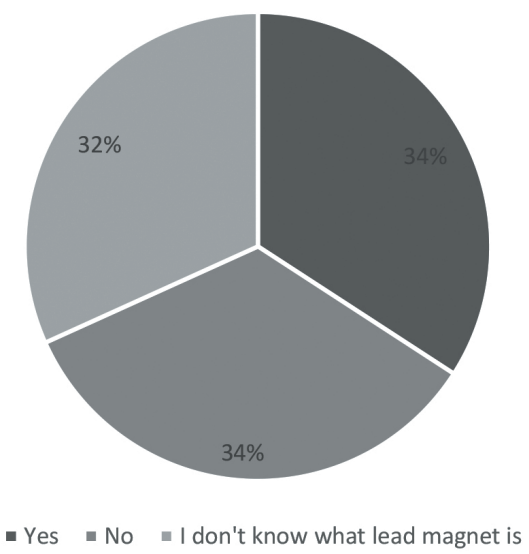

Fig. 2. Lead magnet

Fig. 2. shows the usage of the lead magnet. Almost a third of respondents (32\%) were not familiar with a lead magnet. The percent of respondents who used the lead magnet is equal to the number of those who did not use it. Namely, 34\% of respondents didn't use a lead magnet and 34\% of respondents were actively using a lead magnet. A lead magnet is a free source for potential consumers in return for their e-mail address. These results show a good potential for developing an opportunity for increasing the numbers of subscribers, since the twothirds of respondents either did not offer or were not even familiar with lead magnet advantages.

As a result of the great success of email marketing as a tool for sale increase and building relations with customers, many services that provides e-services to business have appeared. These services are based on what is called software as service- companies subscribe to service and get access to a large number of additional services. When it comes to e-mail services, most of the respondents (51,2\%) use MailChimp. Among the most used services there were Aweber (12,2\%) and Active Campaign (9,8\%). Respondents also use services like ConstantContact, Infusionsoft and GetResponse, but in a slightly lower percentage.

According to results of conducted research 19.5\% of respondents don't have any plan for frequency and timing of sending an e-mail to their subscribers. Almost 
a third of respondents (36.6\%) send messages once or twice a month, while $29.3 \%$ of respondents send messages at least once a week, and $14.6 \%$ of respondents send messages more than once a week. When it comes to message types, there is a variation between the type of sent messages. According to Fig.3, there is a difference between the frequency of sending informational and promotional messages. Research results show that companies send informational messages more often than promotional. In the most cases, info messages are sent once or twice in a month (39\%), unlike the promotional messages which companies send most often, usually once a week (34\%). Unplanned, ad hoc messages have a significant percent according to results of respondent and different types of messages have a similar percentage. This fact leads to the conclusion that companies should consider decreasing of unplanned messages because unplanned communication can easily result in communication failure.

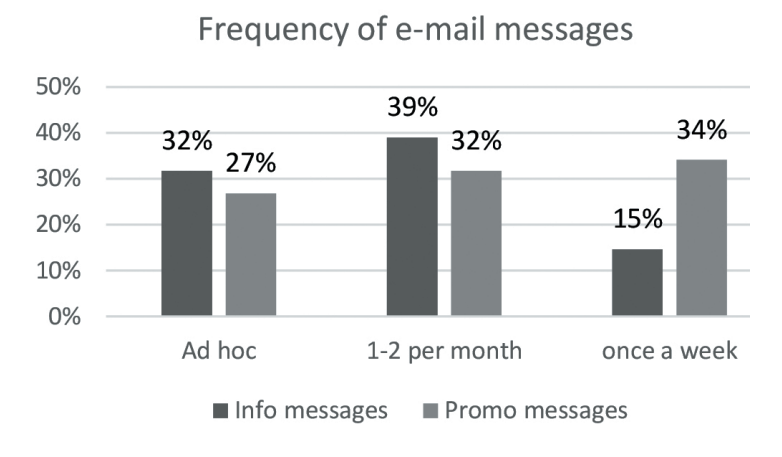

Fig. 3. Frequency of e-mail messages

When it comes to personalizing and segmenting user, companies have realized the benefits. The majority of respondents (68.3\%) use some way of segmenting by different criteria, but $31.7 \%$ don't use segmentation in e-mail marketing. As criteria, for segmenting, companies use different criteria- the interests of subscribers (36.3\%), location $(17.1 \%)$, ages $(4.9 \%)$, gender $(4.9 \%)$ and other (4.8\%)

When it comes to personalization, more than a quarter $(26.8 \%)$ of respondents don't personalize messages at all. Respondents who are using personalized messages as the criteria use customer name (39\%), customer interests (26.8\%).

As it was mentioned, e-mail marketing also brings many challenges for companies. The biggest challenge, according to results were unopened mails $(41,5 \%)$ followed by the problem of e-mail list growth $(36,6 \%)$ and e-mail delivery (14,6\%). Unfounded spam registration, e-mail readings, and click-through rates shared the fourth place $(2,4 \%)$.

Companies use and combine different strategies for increasing e-mail list. According to results of conducted research, Facebook ads were the most popular way of increasing e-mail list. More than half of respondents $(65,9 \%)$ were using Facebook ads for e-mail list increase. Besides the Facebook ads, companies also used SEO (51.2\%), AdWords (36.3\%) and Popup windows (24.4\%).

\section{CONCLUSION}

The development of new technologies has undoubtedly led to big changes in business enterprises. But even in digital era there are still companies which are not familiar with all the advantages of using new marketing tools. Research results have shown that the majority of respondents (60\%) who are employees in small and medium enterprises in Serbia are familiar with e-mail marketing but not many of them integrate it into everyday business strategies. Results show that less than 15\% of respondents are actively using e-mail marketing in marketing and business strategies. This fact leads to the conclusion that there is a lot of space for further development and progress in order to achieve better results by integrating e-mail marketing and all of its advantages into business strategies of entrepreneurs which do business in Serbia. Companies need to start with creating the free content which could be changed for customers e-mail address (lead magnet), sending more info/ newsletter messages to build the interest and draw attention for existing and not just the new customers.

Despite the advantages, companies need to carefully create their strategies if they are planning to involve email marketing. They need to pay attention to e- mail frequency and content which they are sending to subscribers. If companies are sending e-mail without any plan and they don't give a content which is useful for subscribers, that could easily lead companies to the ineffectiveness of email marketing and business failure.

Companies which already integrated new marketing tools need to monitor new trends in digital era. The reason is simple- they need to monitor changes and remodel strategies if it is necessary, in order to remain competitive on the market.

Because of results and all of the advantages, it could be concluded that e- mail marketing as a tool of direct marketing has a lot of space for further development in Serbia. 
Some of the recommendations for further research could be the comparison between the companies which use and don't use e-mail marketing in order to determine the causal relationship between integrating new marketing tools and achieving positive business results.

\section{REFERENCES}

[1] S.Lovreta, J.Končar, G.Petković, Kanali marketinga, CID Ekonomski fakultet u Beogradu, 2011.

[2] R.Eid, and H. El-Gohary, The impact of E-marketing uses on small business enterprises' marketing success. The Service Industries Journal, 33(1), 2013. pp.31-50.

[3] The European Commission, SBA Fact Sheet, Serbia, 2017

[4] J.Stanković, B.Čavić, Trgovina i drugi kanali marketinga, Univerzitet Singidunum, 2013.

[5] R. Stokes, 2011. eMarketing: The Essential Guide to Marketing in a Digital world. Red \& Yellow

[6] D. Ryan, 2014. Understanding digital marketing: marketing strategies for engaging the digital generation.

[7] R. Rettie, Email marketing: success factors. 2002.

[8] B. Specht, Litmus. Retrived 2018. from https:// litmus.com/blog/the-2017-email-client-marketshare-infographic
[9] J. Michie, Street Smart Internet Marketing. Performance Marketing group Inc. 2010.

[10] S. Godin, Permission marketing: Turning strangers into friends and friends into customers. Simon and Schuster. 1999.

[11] K. MacPherson, Permission-based E-mail Marketing that Works!. Kaplan. 2001.

[12] B. Hesirlige Email strategy. Retrieved 2018. from www.pure360.com/10-benefits-of-email-marketing/

[13] O.V. Pavlov, N. Melville, R.K. Plice, Toward a sustainable email marketing infrastructure. Journal of Business Research, 61(11), 2008. pp.1191-1199.

[14] Direct Marketing Association, 2013. Statistical Fact Book

[15] F. Ellis-Chadwick, and N.F. Doherty, Web advertising: The role of e-mail marketing. Journal of Business Research, 65(6), 2012. pp.843-848.

[16] L. Harden, and B. Heyman, Digital engagement: Internet marketing that captures customers and builds intense brand loyalty. AMACOM Div American Mgmt Assn. 2009.

[17] M. Merisavo, and M. Raulas, The impact of e-mail marketing on brand loyalty. Journal of Product \& Brand Management, 13(7), 2004. pp.498-505. 